\title{
Um pequeno tributo para um grande antropólogo
}

A small tribute to a great anthropologist

\author{
Roberto DaMattal, "I \\ 'Pontifícia Universidade Católica do Rio de Janeiro. Rio de Janeiro, Rio de Janeiro, Brasil \\ "Universidade Notre Dame. Indiana, USA
}

Resumo: Este ensaio presta homenagem à obra de Charles Wagley (1913-1991), tomando como base a carreira do autor e revelando como um dos seus estudos foi baseado na obra de Wagley e Eduardo Galvão.

Palavras-chave: Charles Wagley. Eduardo Galvão. Roberto Cardoso de Oliveira. Culturalismo. Estruturalismo. Panema.

Abstract: This essay honors the work of Charles Wagley (1913-1991). The Author contrasts Wagley's and his work to reveal how important Wagley's work was from his work and life as an anthropologist of another generation.

Keywords: Charles Wagley. Eduardo Galvão. Roberto Cardoso de Oliveira. Culturalism. Structuralism. Panema.

DAMATTA, Roberto. Um pequeno tributo para um grande antropólogo. Boletim do Museu Paraense Emílio Goeldi. Ciências Humanas, v. 9, n. 3, p. 617-622, set.-dez. 2014. DOI: http://dx.doi.org/10.1590/1981-81222014000300003.

Autor para correspondência: Roberto DaMatta. Pontifícia Universidade Católica do Rio de Janeiro. Centro de Ciências Sociais. Departamento de Ciências Sociais. Rua Marquês de São Vicente - Gávea. Rio de Janeiro, RJ, Brasil. CEP 22451-900 (damatta.rlk@terra.com.br).

Recebido em 07/12/2012

Aprovado em 22/11/2013

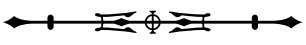


Eu não fui aluno de Charles Wagley e tampouco trabalhei sob sua orientação. Nosso contato, apesar da distância de geração - Chuck foi um dos pioneiros no estudo moderno de grupos tribais brasileiros e de uma antropologia do Brasil em termos holísticos e culturalistas, por meio de um prisma sistemático e acumulativo que buscava objetividade -, foi muito mais marcado pela colegialidade igualitária e, até mesmo adversativa, mas cordial, e por uma forte e preciosa amizade, que brasileiramente nos envolveu como pessoas e como família. Seria, portanto, pretensioso de minha parte procurar realizar aqui um apanhado da obra de Charles Wagley, avaliando suas contribuições para a antropologia cultural e para os estudos brasileiros, porque eu não tive com ele pouca intimidade e, não tendo sido seu discípulo, não sofri da "angústia da influência", que, no dizer de Harold Bloom (em um livro que tem esse título), faz parte da transferência emocional implicada nos laços entre mestres e discípulos, sobretudo, penso eu, em uma disciplina com tanto carisma e tão messiânica como a nossa.

Por esses motivos, não falo de suas perenes contribuições para a antropologia cultural dos índios brasileiros. Optei por fazer uma memória de Wagley, avaliando sua perspectiva teórica em contraste com a de minha geração, repassando de modo breve como usei seus claros relatos etnográficos colhidos na legendária 'comunidade amazônica de Itá'1 e, por fim, falando num tom mais pessoal de meu primeiro encontro com ele no contexto da minha vida e carreira.

Em certo sentido, fiz uma antropologia que, nos anos 1960 e 1970, surgia como paralela, senão como alternativa, ao culturalismo de Charles Wagley, Eduardo Galvão, Egon Schaden, Herbert Baldus, Thales de Azevedo, Luís de Castro Faria, René Ribeiro e outros militantes do ofício no Brasil. Para nós, alunos de Roberto Cardoso de Oliveira, do Museu Nacional, e de David Maybury-Lewis, em Harvard, o escopo era estudar teias de relações humanas como sistemas sociais e estruturas, tirando do conceito de 'cultura' a centralidade básica que ele ocupa no trabalho de todos os estudantes de uma Columbia moldada pelo pensamento absolutamente crítico e fundacional de Franz Boas, do qual foram alunos pesquisadores e escritores do calibre de Alfred Kroeber, Robert H. Lowie (cujos laços com a etnologia brasileira são patentes ${ }^{2}$ ) e Ruth Benedict; sem esquecer Cora DuBois (de quem fui aluno em Harvard no final dos anos 1960), Margaret Mead e Ralph Linton, o grande mentor de Wagley ${ }^{3}$. Esse conceito permeia e transborda na obra dos alunos de Wagley e, no caso de um dos mais excepcionais, Marvin Harris, tem a tonalidade de uma verdadeira contradição na variante chamada de 'materialismo-cultural', um reducionismo que certamente chocaria o próprio Franz Boas.

Em alguns encontros formais, tive discussões teóricas com Wagley. Lembro-me de muitos encontros amistosos, todos marcados pela extrema simpatia e enorme generosidade de Wagley para comigo. Na ocasião em que se reuniu, pela primeira vez no Brasil, um grupo de cientistas para falar da Amazônia sob múltiplos ângulos, em um importante simpósio internacional, realizado entre $6 \mathrm{e}$ 11 de junho de 1966, em Belém do Pará, lembro-me do meu juvenil alvoroço quando Eduardo Galvão se referiu a Roque Laraia, a Júlio Cesar Melatti e a mim como os "Cardoso's boys" - aqueles jovens turcos que só falavam em 'estrutura social'. Para Galvão, nós rejeitávamos o

1 É a cidade de Gurupá, que visitei, em 1974, na grata companhia de um dos seus mais distinguidos discípulos, Emilio Moran, quando realizava um estudo sobre o impacto da rodovia Transamazônica na região do Baixo Amazonas, tomando como base a cidade de Altamira.

2 Veja-se o notável e importante capítulo nove, "Field work in absentia", em Lowie (1959). Nele, Lowie relata seus laços com Curt Nimuendajú e descreve como e por que traduziu e organizou seus textos sobre os Apinayé, os Canela e os Tukuna em inglês, publicandoos nos Estados Unidos.

3 "Neste panorama - diz Wagley em um depoimento importante, talvez o mais completo de sua vida - surgiu em minha carreira o grande mentor que tive, Ralph Linton". Ver Meihy (1990, p. 66).

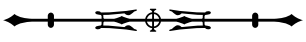


conceito de 'aculturação' e fazíamos parte do projeto de 'estudos de áreas de fricção inter-étnica', que Eduardo Galvão, com seu senso de humor característico, chamava de "projeto Alginex" - o nome de uma conhecida pomada para aliviar dores musculares.

Irritado com a zombaria de Galvão, defendi com as pobres armas de um noviço de vinte e poucos anos o nosso grupo de 'sociólogos comparativos', interessados em traduzir de modo mais claro o chamado 'processo aculturativo', estudando-o em suas contradições sociais e políticas, já que nos encontros interculturais há uma união geográfica (ou espacial) de sociedades linguística e ideologicamente distantes; sobretudo, como ocorria no Brasil, quando elas se representavam dentro dos onipresentes e implacáveis papeis de 'índios' e 'brancos', de 'primitivos' (que impediam o progresso) e 'civilizados'.

Hoje, tudo isso é memória, mas naquela época a crítica tinha como subtexto a ideia de que os interessados em organização social e parentesco abandonavam a diligência no destino das populações tribais e estudavam os índios como se eles fossem "formigas", como gostava de dizer, com seu exagero magnânimo, Darcy Ribeiro. Os fatos concretos, porém, são que Darcy entrou na política, ocupando cargos de grande poder, os índios continuaram a sumir do mapa do Brasil e os "Cardoso's boys", assim como nosso professor e mentor, Roberto Cardoso de Oliveira, falecido em 2006, continuaram a fazer antropologia.

Posso agora ver melhor como o nosso objetivo era reduzido, talvez mais especializado e modesto. Não queríamos documentar todos os aspectos de uma 'cultura' no sentido clássico do termo, quando o pesquisador começa o livro com a história, passa pela organização social e termina com a mitologia. Queríamos aprofundar o estudo de 'sistemas sociais' e da organização social, com centro na família, no parentesco e, eventualmente, no sistema simbólico, que, naquele momento, ganhava um extraordinário impulso com os trabalhos de Claude LéviStrauss, e de suas variantes inglesas antigas e modernas, como fazem prova os trabalhos de Meyer Fortes, Evans-
Pritchard, Raymond Firth, Mary Douglas, Edmund Leach e Victor Turner. Os primeiros eram lidos e estudados por Roberto Cardoso de Oliveira, os últimos foram mais usados pelos antropólogos da minha geração.

Nessa linha, em 1965 ou 1966, retomei, em um curso sobre 'análise estrutural e simbolismo', ministrado na Faculdade Fluminense de Filosofia, em Niterói, os livros "Amazon Town", de Wagley, e "Santos e visagens", de Galvão, ambos fundados em materiais colhidos na mesma época, com a mesma orientação e em uma mesma comunidade do vale do rio Amazonas. No decorrer do curso, encontrei a crença na panema: má-sorte, infortúnio, azar que, como a feitiçaria, atacava caçadores e pescadores em certas circunstâncias. Em virtude da excepcional riqueza etnográfica dos dois estudos, decidi realizar uma tentativa de análise estrutural, tomando como objeto a palavra e o conceito sociocultural nela envolvido. Ao realizar isso, descobri a ideia de panema - uma palavra de origem tupi que significa, de acordo com a tradução feita por Alfredo Augusto da Matta (1937-1938, p. 243) no seu precioso "Contribuição ao estudo do vocabulário amazonense", coisa ruim, desdita e infortúnio. Seu antônimo, como assinala Alfredo da Matta no citado vocabulário, seria murupiara, ou seja, feliz e venturoso. $\bigcirc$ fato de a palavra encontrar-se em um livro publicado em 1937-1938 como parte de um vocabulário corrente na área fala eloquentemente da fusão secular de um legado cultural indígena tupi-guarani (já resultado de uma aculturação) com a língua e as instituições sociais impostas pelos portugueses, conforme assinala a visão pioneira de Charles Wagley.

Meu ensaio sobre a panema é um testemunho do acerto do arcabouço explicativo usado por Wagley sobre, como ele diria, "a cultura" desta área, que, por incrível que pareça, até a publicação de "Amazon Town: a study of Man in the Tropics", em 1953, jamais havia sido objeto de um inquérito etnográfico. Havia um corpo etnográfico e muito mais informações sobre povos que viviam no gelo, nas savanas da África, nas ilhas do Pacífico e no deserto do que sobre as comunidades mestiças que viviam no calor tido 
como insuportável e insalubre dos trópicos. Esses trópicos eram sucessivamente representados na consciência angloeuropeia como doentes, fadados ao fracasso (como demonstrava a experiência de Fordlândia ${ }^{4}$ ), impossíveis de serem alcançados pela civilização e, obviamente, tristes conforme conferiu o grande Lévi-Strauss.

Deste modo, o meu pequeno e certamente deficiente estudo funcional-estruturalista sobre a panema, "Panema: uma tentativa de análise estrutural" (naquele tempo, tudo o que fazia era 'estruturalista'), resgatava da visão culturalista e totalizante de Wagley e Galvão, uma instituição que, por sua vez, remetia de volta para a singularidade de um complexo cultural nascido das atividades de caça e pesca desenvolvidas pelas populações tribais do local, mas compartilhada extensivamente pelos habitantes brasileiros atuais.

Meu estudo confirma os dados de Wagley e Galvão sobre uma cosmovisão, na qual animais e homens, natureza e sociedade, têm obrigações mútuas. $\bigcirc$ destino final da carne de um peixe ou animal apresado que vai se transformar em alimento e, em seguida, em comida, é uma responsabilidade do pescador ou do caçador e deve percorrer um percurso socialmente legitimado. Se a caça ou a pesca caírem em mãos erradas - uma mulher menstruada, grávida, ou se for vendida em um mercado - o seu responsável fica 'empanemado', isto é, começa a não conseguir êxito nas suas empreitadas.

Não cabe aqui fazer a recapitulação do trabalho de um iniciante, publicado no meu primeiro livro, "Ensaios de antropologia estrutural”, em 1973, e na revista L'Homme, em 1967. Mas vale reiterar que o meu estudo foi guiado pelo olhar de Wagley. Um olho revelador da surpresa de encontrar em um mundo em processo de franca modernização individualista, no qual há um cisma inapelável entre cultura e natureza, um mecanismo que religava moralmente animais apresados e a coletividade humana, que, como mostra a crença na panema, tem tanto valor quanto o mundo animal, lido também como uma comunidade.

$$
\text { **** }
$$

Conheci Charles Walter Wagley - 'Wagley', como era chamado por seus colegas no Brasil - no final dos anos 1950, quando eu era estagiário da então Divisão de Antropologia do Museu Nacional e, debaixo da grata orientação de Roberto Cardoso de Oliveira, recebi como tarefa localizar as tribos indígenas do Brasil referidas no importante trabalho de Darcy Ribeiro, "Línguas e culturas indígenas do Brasil", de 1957, em enormes mapas produzidos pelo Instituto Brasileiro de Geografia e Estatística (IBGE). Eu chegava pela manhã ao Museu e, solitariamente, ficava diante de uma pilha de mapas que eram selecionados de acordo com a lista de sociedades tribais do livro de Ribeiro, seguindo a sua localização mais precisa ou provável, de acordo com as coordenadas fornecidas pelo autor. Meu trabalho era justamente o de sincronizar as informações sobre as tribos mencionadas no livro com a sua localização nos mapas, nos quais eu escrevia a lápis e depois à tinta. Era um trabalho que parecia muito fácil, mas requeria bom senso e, sobretudo, muita atenção.

De saída, fui obrigado a inventar uma convenção gráfica para cada grupo, porque Darcy Ribeiro os classificava em termos de níveis de contato com as 'frentes pioneiras' da sociedade brasileira, de modo que eu tinha que distinguir as sociedades tribais "integradas" das que

\footnotetext{
4 No médio rio Tapajós, no estado do Pará, Henry Ford e seus associados implementaram, em 1945, uma enorme empreitada para a fabricação de borracha, em torno da qual se fez um dos maiores projetos de transplante cultural no estilo americano de que se tem notícia. O projeto durou 18 anos, deu um prejuízo de nove milhões de dólares da época e, como mostra Greg Grandin (2009), foi um retumbante fracasso em todos os níveis. Esse fracasso, a meu ver, confirmou não só a malandragem do sistema político brasileiro, como confirmou a impossibilidade de qualquer tipo de implante de alguma coisa 'civilizada' e/ou 'moderna' nos trópicos. Esse desastre vem se somar às tristes memórias dos ciclos de riqueza da borracha na sua primeira e mais gloriosa fase, entre 1880 e 1912, e na segunda, entre 1942 e 1945, quando da Segunda Guerra Mundial.
}

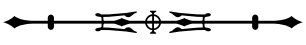


estavam em "contato permanente", "contato intermitente" ou "isoladas" da sociedade brasileira, que para elas surgia na forma de suas "frentes de expansão" ou, como eu chamei mais tarde em um trabalho denominado "Quanto custa ser índio no Brasil?", publicado em 1976, suas várias e nem sempre coincidentes em objetivos e propósitos "agências de contato". Como associar claramente o nome de um grupo tribal ao seu "estágio de integração à sociedade brasileira", relatado no estudo do Darcy Ribeiro? Não foi fácil, mas, mesmo não me lembrando bem, eu consegui realizar um trabalho razoável.

Ao realizar essa tarefa, descobri que nada é simples nas tais 'ciências' ou 'disciplinas' etnográficas. Nem mesmo a trivial tarefa de plotar nomes em mapas, porque os nomes se referiam a sistemas vivos e históricos que, obviamente, mudavam enquanto eu realizava esse trabalho aparentemente mecânico e trivial.

Foi justo em uma dessas tardes em que trabalhava com mapas e nomes de povos indígenas que percebi, pelas saudações alegres e em voz alta, a chegada do tal 'Wagley' à Divisão de Antropologia do Museu Nacional. Fiquei alerta e a postos para recebê-lo, o que não ocorreu porque, em primeiro lugar, ele foi à sala do professor Castro Faria (ambos se conheceram no Rio de Janeiro através do Museu Nacional e de Heloisa Alberto Torres $^{5}$, sua diretora em 1939, quando Wagley iniciou seus estudos sobre os índios Tapirapé!), o qual, por sua vez, levou-o à do Roberto Cardoso de Oliveira, que, por fim e por último, falou do seu trabalho de comparação entre organizações sociais dos grupos tribais brasileiros, inspirado no famoso livro de George Peter Murdock, "Social Structure", publicado em 1949. Cardoso de Oliveira, naquela época, queria realizar um levantamento das sociedades indígenas do Brasil para uma eventual comparação de suas organizações sociais, tal como fez Murdock com 250 sociedades no livro citado.
Eu estava justamente realizando a primeira e, com certeza, a mais humilde etapa deste ambicioso projeto que, como diz o Relatório Anual de 1959 do Museu Nacional, apresentado ao Reitor da Universidade Federal do Rio de Janeiro em 1960, tinha como objetivo colher informações "para uma caracterização operacional das estruturas encontradas", o que, continua o texto, "resultará numa avaliação das possibilidades das fontes, primárias e secundárias, enquanto meios de conhecimento dos sistemas sociais das tribos do Brasil". Foi, pois, durante esse trabalho e o explicando que meu mentor e professor, Cardoso de Oliveira, que já havia participado de uma expedição de Wagley ao Araguaia, em 1957, levou o famoso professor de Columbia à minha mesa, onde ele viu aqueles mapas e eu o vi pela primeira vez como pessoa.

Wagley não ficou indiferente ao projeto nem ao pequeno grupo por ele congregado (Alcida Rita Ramos dele tomava parte, bem como Margarida Chebab, ambas, como eu, estagiários do Museu) e imediatamente o encorajou com sua permanente simpatia e característica generosidade. Creio que, em seguida, ele convidou Cardoso de Oliveira para realizar uma visita de estudo à Universidade de Columbia, o que não ocorreu.

Impossível ficar indiferente à simpatia que emanava e era parte intrínseca da personalidade de Charles Wagley. Simpatia que explicava a sua chegada como um 'herói cultural' em um Museu Nacional que ele conhecia desde o final da década de 1930. Essa foi a primeira impressão que tive de sua pessoa. Ali estava o primeiro professor de antropologia cultural da famosa Universidade de Columbia, que conheci na minha vida, e esse professor e pesquisador, profundo conhecedor dos 'índios do Brasil', comportava-se de modo não professoral, distante, condescendente ou autoritário. Foi assim, diante de uma velha mesa coberta de mapas, que o conheci.

\footnotetext{
5 Para efeitos históricos, registro que com ela convivi como conselheiro suplente do Museu Nacional, no Conselho Nacional de Proteção aos Índios, por alguns meses a partir de agosto de 1965. Dela tive a mesmíssima impressão de Wagley, tal como ela surge na entrevista concedida a Bom Mehy.
} 
De certo modo, a memória dos que partiram para o grande mapa dos mortos é um relicário: aquilo que eles deixaram dentro de cada um de nós. Todos, porém, deixam apenas relíquias individuais na forma de lembranças positivas ou negativas do que, no Brasil, chamamos de saudade. No caso de Charles Wagley, ou Chuck, como ele era, para minha surpresa, chamado por seus amigos, colegas e ex-alunos (pois, como é que se pode, dizia um lado meu, chamar um professor da Universidade de Columbia por um mero apelido...), porém, há uma vasta obra realizada com muita tenacidade e total entrega pessoal por muitas décadas. Uma obra que ressurge como um vasto legado na forma de ex-alunos, de discípulos, de colegas e da comunidade antropológica em geral. A teia humana que todos formamos ao longo de nossas vidas.

***

Nesta passagem de 2012 para 2013, quando Charles Wagley faz 100 anos e eu escrevo estas linhas, quero exprimir o quanto me sinto feliz e honrado com o convite para escrever esse pequeno tributo à sua pessoa e ao seu vasto e generoso legado ao lado de seus antigos alunos e colaboradores. Como disse, eu não fui seu aluno ou discípulo, mas fui seu admirador e seguidor. Ambos estudamos sociedades indígenas e vivemos toda a nossa vida entre Brasil e Estados Unidos; ambos passamos por aventuras semelhantes estudando humildes sociedades tribais com a mesma ausência de heroísmo salvacionista, que toma os perigos e as agruras como parte da profissão; ambos ensinamos com total dedicação aos nossos alunos tanto no Brasil quanto nos Estados Unidos; e ambos escrevemos sobre o Brasil como um sistema social mais do que como uma economia, um país em desenvolvimento, um sistema político a ser aprimorado e um Estado Nacional.

Ao reler e ler com outros olhos os escritos de Wagley e ao comungar de seus sentimentos, esperanças e propósitos, bem como de sua intimidade com o imenso e milagroso poder da literatura, fiquei deslumbrado. Primeiro, pela originalidade, depois pela coragem, em seguida pela determinação e, finalmente, pela limpidez do estilo, revelador de uma enorme honestidade e de um raro preparo intelectual. Reler Wagley foi um prazer; lembrá-lo foi uma saudade; pensar na sua falecida esposa, Cecília Roxo Wagley, nos seus filhos e na sua família, uma grande emoção porque estou e sou profundamente ligado por laços de amizade a Conrad Phillip Kottak, seu ex-aluno e genro, um colega cuja obra eu muito admiro, a sua esposa Betty Wagley Kottak e aos seus filhos e netos por profundos laços de carinho. Obrigado pela distinção de poder escrever essas linhas e rever esses fatos, que ligam nossas vidas à vida de um grande antropólogo - que foi, antes de tudo, um homem bom.

\section{REFERÊNCIAS}

GRANDIN, Greg. Fordlândia: ascensão e queda da cidade esquecida de Henry Ford na selva. Rio de Janeiro: Rocco, 2009.

LOWIE, Robert H. Ethnologist: a personal record. Berkeley: University of California Press, 1959.

MATTA, Alfredo Augusto da. Contribuição ao estudo do vocabulário amazonense. Revista do Instituto Geográfico e Histórico do Amazonas, v. 6, n. 1-2, p. 21-332, 1937-1938.

MEIHY, José Carlos Sebe Bom. A colônia brasilianista: história oral de vida acadêmica. São Paulo: Nova Stella, 1990. 